\title{
Modeling damaged precast structural system when its robustness checks
}

\author{
Viktar TUR ${ }^{* 1,3}$, Andrei TUR ${ }^{2}$, and Aliaksandr LIZAHUB ${ }^{2}$ \\ ${ }^{1}$ Head the Department of Concrete Technology and Construction Materials, Brest State Technical University, Belarus \\ ${ }^{2}$ Department of Building Structures, Brest State Technical University, Belarus \\ ${ }^{3}$ Department of Building Structures, Bialystok University of Technology, Poland
}

\begin{abstract}
Within the framework of traditional approaches to checking for resistance of reinforced concrete buildings and structures to the progressive collapse development, membrane (chain) forces in a damaged structural system are calculated separately, without considering its non-linear bending behavior during the formation of the plastic hinges and without checking the possibility of achieving large deflections.

The authors propose an approach to modelling a nonlinear quasi-static reaction of a damaged structural system in an accidental design situation. This approach considers non-linear bending and the resistance of reserved horizontal ties, considering their ultimate ductility. The authors verified the proposed approach based on the results of experimental studies by others researchers.

An example of the application of the proposed approach in assessing the robustness of a structural system made of precast concrete with a sudden removal of the central column is considered. In accordance with the provisions of the energy approach, an analysis is made of the contribution of individual resistance mechanisms to the total quasi-static and dynamic resistance of the damaged structural system.

We show that the proposed calculation model adequately describes the behavior of a damaged structural system in an accidental design situation, and therefore to carry out parametric studies and check the robustness of building structures.
\end{abstract}

Keywords: robustness, resistance mechanism, progressive collapse, dynamic resistance, energy balance method

\section{Introduction}

Robustness is an important property of a structural system. A structural system has robustness if, after a hazard appears, the assigned exploitation functions (evacuation of people, repairs, inspection, etc.) are performed within a limited time interval. The list of hazards includes accidental actions and consequences of significant human error that can occur during the design, construction, exploitation and dismantling of a structural system. It should be noted that the target reliability parameters given in the standards $[4,8,11,13,20,21]$ and used for the calibrations of the partial factors when the limit states checking do not consider human errors at all stages of the structure's lifetime.

In modern scientific and technical literature, the definition of the term "robustness" presents variously $[1,6,9,12$, $14,22]$. Most sources associate the definition of the term "robustness" mainly with the phenomenon of progressive collapse. Only a few sources, for example in [12], consider robustness as an aspect of the safety of a structural system.

In the general case, the term "robustness" defines as the ability of a structural system to withstand accidental events without being damaged to an extent disproportionate to the original case.

In the current standards $[4,8,11,13,20,21]$ the requirement for robustness checking is implicit where an accidental situation is caused by events such as fires, explosions, impacts of vehicles in parts of the building, the consequences of human errors made at various stages of the structure's lifetime.

The draft new fib MC2020 develops provisions related to the assessment of the robustness of structural systems, which are based on the risk assessment format as presented in ISO 2394:2015 (2015). According to fib MC2020 structural robustness checks should include the following basic steps: (1) identification of the intended hazard $(\mathrm{H})$ or

*Corresponding author: E-mail address: profturvic@gmail.com (Viktar TUR) 
the list of hazards to which the structural system is likely to be exposed during a lifetime. At the same time, it should be taken into account that we may not identify some hazards at the designing stage (for example, terrorist and / or criminal attacks); (2) determination of the local resistance of an individual key element (D). This mainly applies to designing the key structural components to withstand every load (for example, a wall panel in a household gas explosion); (3) determination of subsequent indirect damage to the system (S) following direct local failure, also described as progressive collapse; (4) quantifying the values of direct $\mathrm{C}_{\text {dir }}$ and indirect $\mathrm{C}_{\text {ind }}$ consequences, including economic, social, environmental losses, as well as the cost of loss of human lives (human victims) in monetary terms according to ISO 2394:2015 [16]. Direct costs (damage) are usually localized as a result of damage to individual structural elements, while indirect losses are associated with the loss of system functionality as a result of the implementation of direct losses. The total risk $\mathrm{R}_{t o t}$ associated with a system failure in an accidental design situation is calculated according to ISO 2394:2015 [16].

As a rule, accurate and simplified design procedures are used to assess the robustness of a structural system and to analyze the conditions for the occurrence of progressive collapse.

Under the accurate procedure, accidental actions and effects of actions are simulated for all possible scenarios for implementing a hazard (set of hazards). The structural elements of the system are checked for accidental combinations of loads, and with a local failure appears the damaged structural system checks. After that, the consequences of the collapse are assessed in terms of the number of victims, economic, environmental and other losses in monetary terms and the total risks are calculated.

The simplified procedure considers an accidental design situation, according to which any structural element that affects the resistance of the entire structural system receives irreversible damage and loses its function. Here, the damaged structural system is analyzed with the key element removed. The criteria are checked that the damaged system is able to withstand the acting loads (accidental combinations of loads) with the assigned reliability level for a certain relatively short time interval, which is necessary for evacuating people, performing repairs, enforcement or dismantling a building structure. For some specific structural systems, moreover, it is necessary to reserve time to clarify the causes of the collapse.

The target reliability index (target reliability level) of a damaged system with alternative load paths depends on the target reliability level of the original intact system for the considered assignment period (hours, days, months) and the probability that the considered element is removed for reasons other than those considered in the design. Issues related to the assignment of a target reliability index when checking the robustness of structural systems are considered, for example, in [23].

The main strategies for protecting structural systems from progressive collapse and requirements for assessing the robustness of reinforced concrete structural systems are detailed in $[1,8,11,17,19,25]$.

The alternative load path strategy (ALP) explicitly considers the resistance of a damaged structural system to progressive collapse (i.e., "indirect" or "following ..."), when the degree of initial damage to the structural system has already been established (forced, according to special rules, removed from the structural system key elements). Therefore, this strategy is considered as a way to reduce the probability $\mathrm{P}[\mathrm{S} \mid \mathrm{D} \cap \mathrm{H}]$. This strategy accepts that some components of the system will fail, but requires that the total damage of the system is limited. When applying this strategy, it has to be verified that the structure has sufficient redundancy and possibilities to mobilize so-called alternative load paths. Redundancy significantly increases system robustness, and is often the only viable means of ensuring sufficient robustness. On the other hand, achieving redundancy may be difficult and/or expensive, and is therefore often limited to critical parts of the system [13]. Measures to reduce the probability $\mathrm{P}[\mathrm{S} \mid \mathrm{D} \cap \mathrm{H}] \mathrm{under}$ this strategy include:

- development of an integrated system of horizontal and vertical ties that ensure the perception of an accidental combination of effects (at $\mathrm{Ad}=0$ ) and the redistribution of forces in the damaged system, considering the chain (membrane) forces arising in the plates and beams of the deformed system (provided the possibility of realizing large deflections), as well as beam effects in the walls;

- design of reserve load-bearing elements in the system, creation of reserves of resistance of elements and limitation of the number of structural components that can receive irreversible local damage under applying an accidental load.

The strategy to mitigate the consequences of failure aims to limit the unacceptable (disproportionate) consequences $\left(\mathrm{C}_{\text {ind }}\right.$ and/or $\left.\mathrm{P}[\mathrm{S} \mid \mathrm{D} \cap \mathrm{H}]\right)$ resulting from the occurring of local damage D. This strategy provides the 
requirements for the layout of the structural system (for example, changing the direction of spans in ribbed floor slabs), the space-planning solution of the building (building structure), as well as its location on the master plan.

The event control strategy $(\mathrm{P}(\mathrm{H}))$ includes measures to prevent a pre-identified set of hazards $(\mathrm{H})$ and limits the frequency of their occurrence to an acceptable level. This strategy does not affect the resistance of the structural system. Hazard control measures include, for example, site selection, restrictions on the use of a building structure, installation of security control systems, protective barriers, etc. In addition, these measures include quality control during design to prevent human error and recommendations for maintenance.

The key element design strategy focuses on preventing localized damage D (often referred to as "direct failure"), which is directly caused by threat $\mathrm{H}$, and reducing the likelihood of $\mathrm{P}[\mathrm{D} \mid \mathrm{H}]$. Key elements are understood as elements and connections that are necessary to ensure the resistance of the entire structural system as a whole.

Membrane or chain forces should be considered as the second line of protection of the structural system from progressive collapse, provided that the damaged structural system is able to mobilize alternative load paths and continuity and ductility will be provided in the floor elements (beams and slabs) after reaching large deflections. In traditional approaches, on which it based the design relationships of the structural standards [2, 4, 8, 11, 13, 15, 20,21], chain (membrane) forces in a deformed structural system are calculated separately, without considering its nonlinear bending behavior and without checking the large deflections.

The resistance to the progressive collapse of damaged structural systems largely depends on the dynamic effects during the transition to a deformed scheme after the implementation of hazard and failure of the key element. Computational models for checking the robustness of such structural systems take advantage of the large displacement method and the effects of ductility of ties (in butt joints). The main provisions of a simplified model for calculating damaged systems with alternative load paths were formulated in [17, 24-27].

\section{Modeling the total nonlinear response of a damaged structural system considering bending resistance and chain (membrane) forces}

\subsection{General requirements for the numerical model}

In the general case, the constitutive principles of macro-modeling should be used for the development of a finite element model (FEM) which applies to the analysis and evaluation of the quasi-static or dynamic response of a damaged structural system under accidental load combination. The choice of model type for a given structural system involves a balance between reliability, practicality, and computational efficiency, subject to the capabilities of available software and computational resources. Linear elastic behavior beams and slabs modeled the elastic behavior of the structural system, and non-linear behavior of the structural system completely depends on the adopted models of the plastic hinges, which insert into certain sections of elements of the structural system according to the accepted rules. The places of plastic hinges "insertion" into the structural components should be determined a priori based on a qualified engineer qualitative understanding of the expected mode of failure of the damaged structural system. Plastic hinge models have the advantage of being computationally efficient by modeling highly nonlinear effects in localized regions of the structure with few degrees of freedom.

When a key element removing from the structure, in the $\mathrm{RC}$ frame the beam-end-moment initially develops. At this stage, moment plastic hinges appear in the near-support regions and relatively small deflections are observed at the joint where the key element is removed. With the further development of deflections, a transition to chain (membrane) effects occurs. It should be noted that in most practical cases, when the robustness of damaged structural systems checks, researchers and designers consider bending behavior only without accounting membrane effects, or vice versa. At the same time, it is assumed that an integrated system of horizontal and vertical ties will allow to mobilize an alternative load path and "to bridge over or around the damaged volume of the area without progressive collapse developing from the local damage" [10]. The design of the tie elements is carried out based on the static equilibrium deflected system only without considering the ductility of the steel ties and bond-slip effects. When dynamic resistance of the damaged system assesses based on the energy balance method (EBM), it is important to know the complete nonlinear system response "F- $\delta$ " ("force-deflection") at the joint with removed element, which considers both the bending and membrane behavior description. Here, the alternative load path should be designed in such a way that the transition from one resistance mechanism to another should be smooth with minimal dynamic effects.

The moment plastic hinges simulate the bending resistance mechanism. Their behavior under static loading 
describes with usage the relationships "moment-curvature" ("M- $\phi$ ") or "moment-angle of rotation" ("M- $\theta$ ") (for the known plastic hinge length) (Figure 1a). The values of the parametric points of the "M- $\phi$ " and "M- $\theta$ " diagrams depend on the geometric sizes of the cross-sections, the reinforcement coefficient, and the mechanical properties of the materials. Therefore, when a nonlinear analysis of reinforced concrete structures performs, full stress-strain relationships for concrete and reinforcing steel with the average values for the main parametric points are used, according to SP 5.03.01-2020 [21]. To ensure the required level of reliability, the design resistance of the system should be assessed with the usage of the global safety factor, the value of which is determined, for example, according to [23].

a)

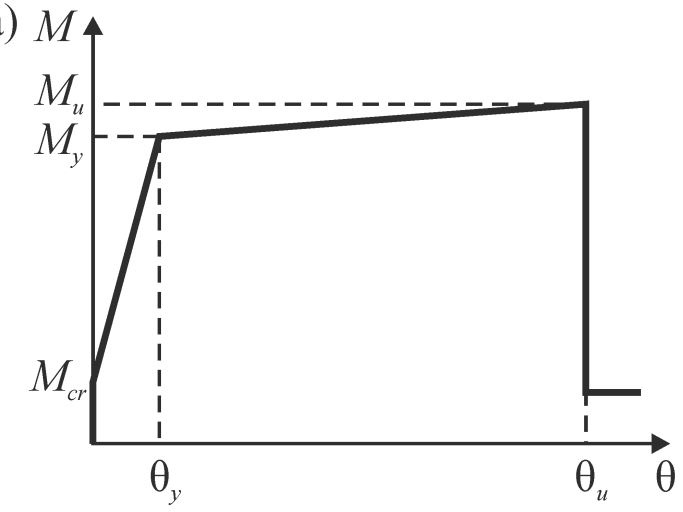

b) $N$ (

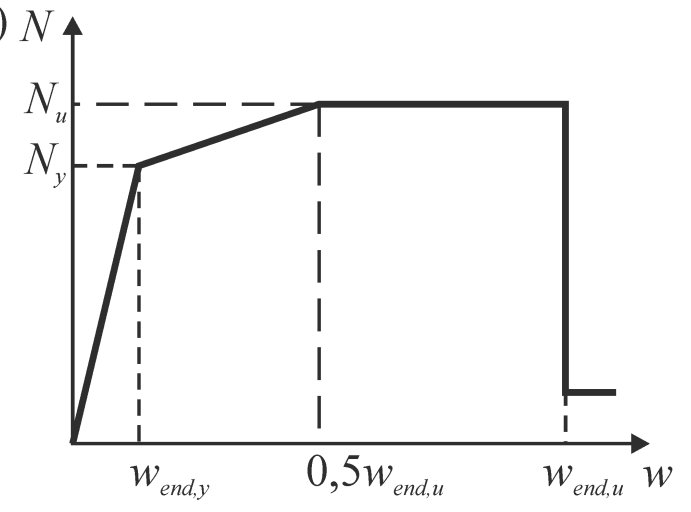

Figure 1. General view of the idealized "M- $\theta$ " (a) and "N-w" (b) diagrams

For reinforced concrete frames, typical places where the formation of moment plastic hinges observed are beamcolumn joints. Here the maximum values of bending moments are observed. For flat floor slabs, it's assumed that the linear plastic hinge forms along the yield line, the position of which should be determined considering the boundary and loading conditions. For the flat slabs and beams, it is necessary to consider the shear (punching) behavior and we should account it for in the numerical model.

With the development of large deflections in the joint with removed support (column, part of wall), the structural elements (beams and floor slabs) try to move inward. When the horizontal displacements of the edges of the structural element restrain, tensile forces in the restraint ties arise and so-called chain or catenary forces developed. To simulate such effects, an axial bond-slip plastic hinge can be proposed. The "tensile force-longitudinal displacement" relationship describes this type of hinge (see Figure 1b).

Table 1 shows an example of determining the values of the parametric points of the relationship "longitudinal force-longitudinal displacement", calculated under the "bond-slip" model [3, 5] applied to the case of horizontal ties anchored in adjacent spans.

A significant role in ensuring the robustness of the damaged structural system plays the ability to large plastic deformation development (ductility) of their tie elements. It can be concluded that it is more preferable to use reinforcement with higher deformability as ties (for example, S240 class, instead of S500). "Bond-slip" effects should also be reflected in the "longitudinal force-longitudinal displacement" relationship.

It is important to consider geometric nonlinearity (P-delta and large displacement effects) in the calculation procedures when membrane effects modeling.

The nonlinear quasi-static numerical FE-model allows to determine the force-deflection response of the damaged structural system, taking into account the chain (membrane) effects, and then, based on the energy balance method (EBM) approaches to determine its dynamic response. Energy balance method (EBM) can be applied both for prefabricated reinforced concrete structures with a system of horizontal and vertical ties, and for monolithic structural systems, where the role of ties can be played by a longitudinal reinforcement of structural elements. At the tensile membrane action (TMA) stage, significant tensile forces arise in structural elements, which can be redistributed at the longitudinal reinforcement bars provided it is sufficiently anchored, for example, in adjacent spans.

After reaching a certain level of deflections, tensile stresses develop in the entire height of the cross-section of the element. As a result, both the upper and lower reinforcement perceives the chain (membrane) forces. 
Table 1. Expressions for assessment of the parametric points of the "N-w" diagram

\begin{tabular}{|c|c|c|c|}
\hline Variable & $\begin{array}{c}\text { Symbol } \\
\text { [units] }\end{array}$ & Equastion & Example $^{(3)}$ \\
\hline $\begin{array}{l}\text { 1. Longitudinal force corresponding } \\
\text { to the yield of steel }\end{array}$ & $N_{y}[\mathrm{kN}]$ & $N_{y}=A_{s t} \cdot f_{y d}$ & $101 \mathrm{kN}$ \\
\hline $\begin{array}{l}\text { 2. Longitudinal force corresponding } \\
\text { to the rupture of the bar }\end{array}$ & $N_{u}[\mathrm{kN}]$ & $N_{u}=1.08 \cdot N_{y}$ & $109 \mathrm{kN}$ \\
\hline $\begin{array}{l}\text { 3.Longitudinal displacement corresponding } \\
\text { to the yield strength of the steel }\end{array}$ & $w_{\text {endy }}[\mathrm{mm}]$ & $w_{e n d, y}=0.288 \cdot\left(\frac{\phi \cdot f_{y d}^{2}}{\tau_{b, \max } \cdot E_{S}}\right)^{0.714}+\frac{f_{y d}}{E_{s}} \cdot 2 \cdot \phi$ & $0.468 \mathrm{~mm}$ \\
\hline $\begin{array}{c}\text { 4. Length of th e stress } \\
\text { transfer zone immediately after yield }\end{array}$ & $l_{t y}[\mathrm{~mm}]$ & $l_{t}=0.583 \cdot \frac{\phi \cdot f_{y d}}{\tau_{b, \max } \cdot S_{\text {end,net }}^{0.4}}+2 \cdot \phi$ & $548 \mathrm{~mm}$ \\
\hline $\begin{array}{l}\text { 5. The length of the plastic } \\
\text { deformation zone }\end{array}$ & $l_{t, p l}[\mathrm{~mm}]$ & $l_{t, p l}=\frac{F_{s u}-F_{s y}}{\tau_{b m, p l} \cdot \pi \cdot \phi}=\left(\frac{f_{u d}-f_{y d}}{\tau_{b m, p l}}\right) \cdot \frac{\phi}{4}$ & $44.9 \mathrm{~mm}$ \\
\hline 6.Ultimate longitudinal displacement & $w_{\text {end }, u}[\mathrm{~mm}]$ & $w_{e n d, u}=l_{t, p l} \cdot \epsilon_{s m, p l}+w_{e n d, y}$ & $1.59 \mathrm{~mm}$ \\
\hline \multicolumn{4}{|c|}{$\begin{array}{l}\text { Notes: } \\
\text { 1) Maximum value of bond stress } \tau_{b, \max } \text { is determined by the formula } \tau_{b, \max }=2.5 \cdot \sqrt{f}_{c m} \\
\text { where } f_{c m}=f_{c k}+8 \mathrm{~N} / \mathrm{mm}^{2} \\
\text { 2) General view of the "N-w" diagram see from Figure } 1 \mathrm{~b} \text {; } \\
\text { 3) Values are given for a tie rebar } \phi 16 \mathrm{~S} 500 \text { (class B), embedded in concrete } \mathrm{C} 20 / 25 \text {. }\end{array}$} \\
\hline
\end{tabular}

\subsection{Validation of the developed FE-model}

\subsubsection{Description of the experimental frames}

The numerical FE-model have been validated based on the test results and observations, which were obtained by testing a full-scale two-span reinforced concrete frame at the NIST laboratory in 2011 [18]. Two specimens (IMF and SMF) designed in accordance with the requirements of ACI 318-02 were tested (see Figure 2). Specimen SMF was designed for seismic requirements. The tests were carried out with control of vertical displacements in the central joint. Large vertical deflections and chain (membrane) effects were achieved in both specimens.

a)

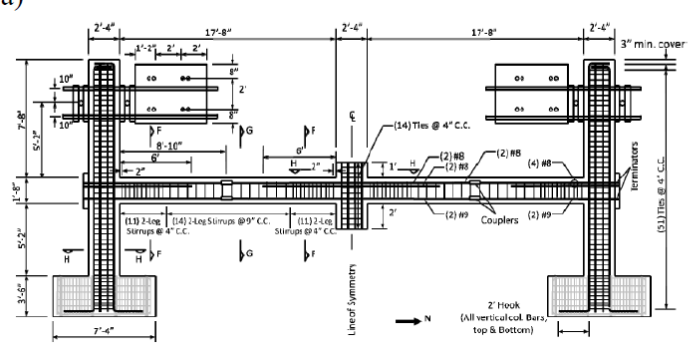

b)

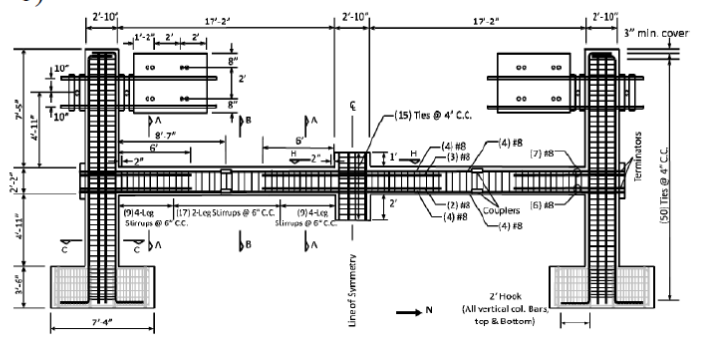

c)

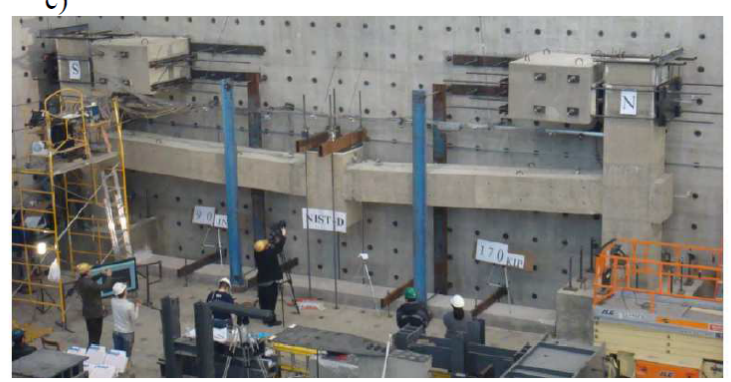

Figure 2. Reinforcement and dimensions of IMF-specimen (a) and SMF-specimen (b); general view of testing the SMF-specimen (c) [18]

Figure 2 shows the geometric dimensions of the specimens and the general view of the test setup. The average values of the concrete compressive and tensile strength are listed in Table 2. The average mechanical properties of the steel reinforcing bars are given in Table 3. The authors [18] presented more details of the experimental studies 
and results.

Table 2. Average values of the concrete compressive and tensile strength at the time of testing [18]

\begin{tabular}{|c|c|c|c|}
\hline \multirow{2}{*}{ Specimen } & \multicolumn{2}{|c|}{ Compressive Strenght $f_{c m}, \mathrm{MPa}$} & Split Cylinder Tensile Strength $f_{c t}$ MП a \\
\cline { 2 - 4 } & Footings & Beams and Columns & Beams and Columns \\
\hline IMF & 39 & 32 & 3.1 \\
\hline SMF & 37 & 36 & 2.9 \\
\hline
\end{tabular}

Table 3. Average values of parametric points of the deformation diagram of reinforcing bars [18]

\begin{tabular}{|c|c|c|c|c|c|}
\hline $\begin{array}{c}\text { Marking according } \\
\text { to ASTM A706 } \\
\text {-Grade } 60\end{array}$ & $\begin{array}{c}\text { Bar diameter, } \\
\mathrm{mm}\end{array}$ & $\begin{array}{l}\text { Yield Strength } \\
f_{y}, \mathrm{MPa}\end{array}$ & $\begin{array}{c}\text { Ultimate Strength } \\
f_{u}, \mathrm{MPa}\end{array}$ & $\begin{array}{c}\text { Rupture Strain } \\
\%\end{array}$ & Note \\
\hline$\# 8$ & 25.4 & 476 & 648 & 21 & 1 \\
\hline$\# 9$ & 28.7 & 462 & 641 & 18 & 2 \\
\hline$\# 9$ & 28.7 & 483 & 690 & 17 & 3 \\
\hline$\# 10$ & 32.3 & 503 & 731 & 16 & 4 \\
\hline$\# 4$ & 12.7 & $524^{*}$ & 710 & 14 & 5 \\
\hline$\# 4$ & 12.7 & $545^{*}$ & 676 & 15 & 6 \\
\hline \multicolumn{6}{|c|}{$\begin{array}{l}\text { Notes: *offset yield strength, } \varepsilon_{y}=0,2 \% \text {; } \\
\text { 1) Top bars in beam of IMF specimen and all beam reinforcement in SMF specimen; } \\
\text { 2) Bottom bars in beam of IMF specimen; } \\
\text { 3) Vertical bars in columns of IMF specimen; } \\
\text { 4) Vertical bars in columns of SMF specimen; } \\
\text { 5) Ties and stirrups in IMF specimen; } \\
\text { 6) Ties and stirrups in SMF specimen. }\end{array}$} \\
\hline
\end{tabular}

\subsubsection{Development of the FE-model of the experimental frames}

In the numerical FE-model columns and beams are modeled by beam linear-elastic finite elements. The rigid body element models column-to-beam joints. At the end of the beams, moment plastic hinges and axial tensile bond-slip plastic hinges are inserted into the beam and column finite elements. Also, moment plastic hinges have been inserted in columns as shown in Figure 3.

Nonlinear quasi-static analysis was performed with control of vertical displacements. A displacement-controlled vertical load is imposed on the frame until the failure of the frame. SAP2000 is employed to perform the static nonlinear pushdown analysis. Note that geometrical nonlinearity of the system at large deflections is taken into account.

\section{Moment plastic hinge. "Bending moment-rotation angle" diagram}

The moment plastic hinge is described by the "moment-rotation angle" relationship, which is obtained from the "moment-curvature" ("M- $\phi$ ") relationship for the critical sections. In the first approximation, the length of the moment plastic hinge used for the transformation of the "moment-curvature" relationship into the "moment-angle of rotation" diagram assumes to equal to the effective section depth (based on the characteristic crack patterns registered in the experiments).

The yielding moment $\mathrm{M}_{y}$ and the ultimate bending moment $\mathrm{M}_{u}$, as well as the corresponding values of curvature $\phi_{y}$ and $\phi_{u}$, are obtained from considering the cross-section resistance model (Table 4).

\section{Axial bond-slip plastic hinge}

As was shown above, we describe axial plastic hinges using "N-w" diagrams ("longitudinal forces-longitudinal displacements") for steel bars embedded in concrete. Table 5 lists the values of the basic parametric points of the 


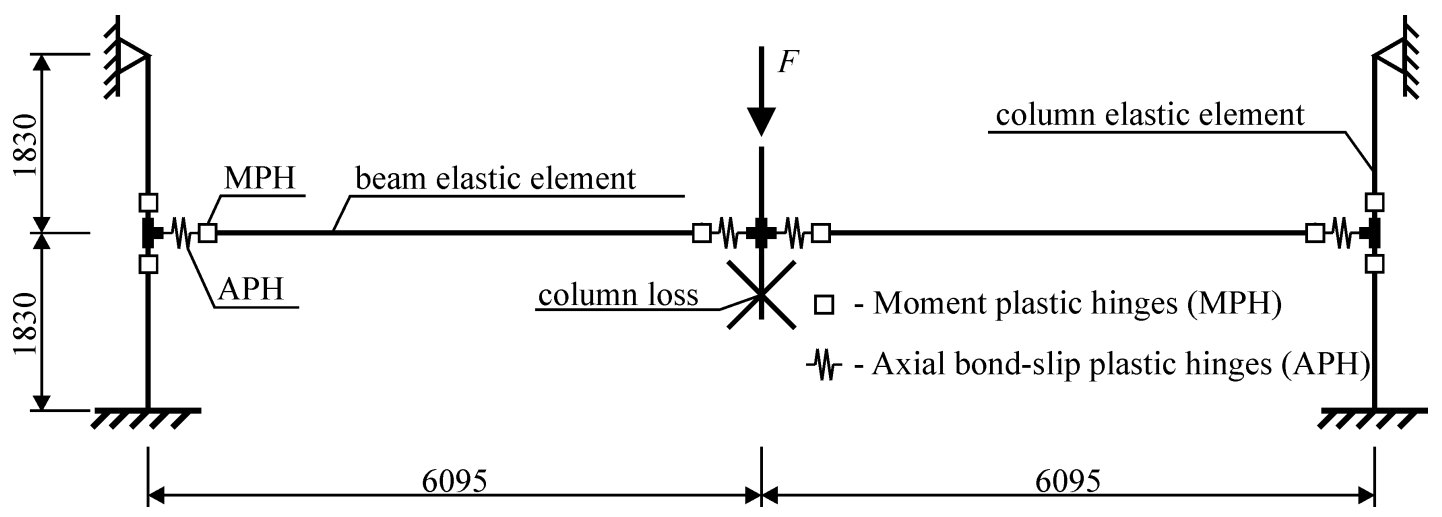

Figure 3. FE-model with embedded hinges

Table 4. Parametric points of the "moment-curvature" diagram for moment plastic hinges

\begin{tabular}{|c|c|c|c|c|c|c|c|}
\hline \multirow[b]{2}{*}{ Specimen } & \multirow[b]{2}{*}{ Member } & & \multicolumn{3}{|c|}{ Bending moment } & \multicolumn{2}{|c|}{ Curvature } \\
\hline & & Cross-section (1) & $\begin{array}{c}M_{c r}^{(2)} \\
\mathrm{N} \cdot \mathrm{mm}\end{array}$ & $\begin{array}{c}M_{y} \\
\mathrm{~N} \cdot \mathrm{mm}\end{array}$ & $\begin{array}{c}M_{u} \\
\mathrm{~N} \cdot \mathrm{mm}\end{array}$ & $\phi_{y} 1 / \mathrm{mm}$ & $\phi_{u} 1 / \mathrm{mm}$ \\
\hline \multirow{3}{*}{ IMF } & Beam & 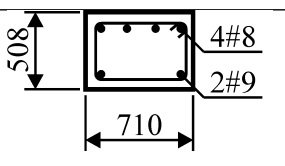 & $9.47 \mathrm{E}+07$ & $2.56 \mathrm{E}+08$ & $2.83 \mathrm{E}+08$ & $6,26 \mathrm{E}-06$ & $7,72 \mathrm{E}-05$ \\
\hline & Beam & $\stackrel{710}{\longrightarrow}$ & $9.47 \mathrm{E}+07$ & $3.97 \mathrm{E}+08$ & $4.31 \mathrm{E}+08$ & $6.67 \mathrm{E}-06$ & $6.38 \mathrm{E}-05$ \\
\hline & Column & $\stackrel{710}{\longleftrightarrow}$ & $1.85 \mathrm{E}+08$ & $8.77 \mathrm{E}+08$ & $1.14 \mathrm{E}+09$ & $4.74 \mathrm{E}-06$ & $3.60 \mathrm{E}-05$ \\
\hline \multirow{3}{*}{$\mathrm{SMF}$} & Beam & $\stackrel{864}{\longrightarrow}$ & $1.82 \mathrm{E}+08$ & $7.63 \mathrm{E}+08$ & $8.77 \mathrm{E}+08$ & $5.04 \mathrm{E}-06$ & $4.97 \mathrm{E}-05$ \\
\hline & Beam & $\stackrel{864}{\longleftrightarrow}$ & $1.82 \mathrm{E}+08$ & $8.67 \mathrm{E}+08$ & $9.94 \mathrm{E}+08$ & $5.15 \mathrm{E}-06$ & $4.83 \mathrm{E}-05$ \\
\hline & Column & $\stackrel{864}{\longrightarrow}$ & $3.12 \mathrm{E}+08$ & $1.40 \mathrm{E}+09$ & $1.86 \mathrm{E}+09$ & $3.85 \mathrm{E}-06$ & $3.57 \mathrm{E}-05$ \\
\hline \multicolumn{8}{|c|}{$\begin{array}{l}\text { Notes: } \\
\text { 1) Cross-sections in the table are oriented so that the tensioned edge is at the } \\
\text { bottom, and the compressed edge is at the top; } \\
\text { 2) } M_{c r} \text { is the bending moment corresponding to the beginning of cracking; } \\
\text { 3) General view of the "moment-curvature" diagram see Figure 1a. }\end{array}$} \\
\hline
\end{tabular}

"N-w" relationship calculated under $[3,5]$. The main mechanical properties of reinforcing bars are taken in accordance with the Table 3. 
Table 5. Parametric points of the "N-w" diagram for axial plastic hinges in beams

\begin{tabular}{|c|c|c|c|c|c|c|}
\hline \multirow{3}{*}{ Specimen } & \multirow{3}{*}{\multicolumn{2}{|c|}{ Reinforcement / diametr }} & \multicolumn{4}{|c|}{ Basic parametric points of the "N-w" relationship } \\
\hline & & & \multirow{2}{*}{$\frac{N_{y}}{\mathrm{kN}}$} & \multirow{2}{*}{$\begin{array}{l}N_{u} \\
\mathrm{kN}\end{array}$} & \multirow{2}{*}{$\frac{w_{\text {end,y }}}{\mathrm{mm}}$} & \multirow{2}{*}{$\begin{array}{c}w_{\text {end,u }} \\
\mathrm{mm}\end{array}$} \\
\hline & & & & & & \\
\hline \multirow[t]{2}{*}{$\mathrm{IMF}$} & top & $4 \phi 25.4$ & 936.40 & 1299.20 & 0.58 & 54.16 \\
\hline & bottom & $2 \phi 28.7$ & 597.76 & 829.36 & 0.63 & 61.18 \\
\hline \multirow[t]{2}{*}{$\mathrm{SMF}$} & top & $7 \phi 25.4$ & 1638.69 & 2273.60 & 0.56 & 51.07 \\
\hline & bottom & $6 \phi 25.4$ & 1404.59 & 1948.80 & 0.56 & 51.07 \\
\hline
\end{tabular}

\subsubsection{Results of the numerical simulation and discussion}

Figure 4 shows the "F- $\delta$ " curves simulated with usage proposed FE-model and obtained in the experiment given in [18].
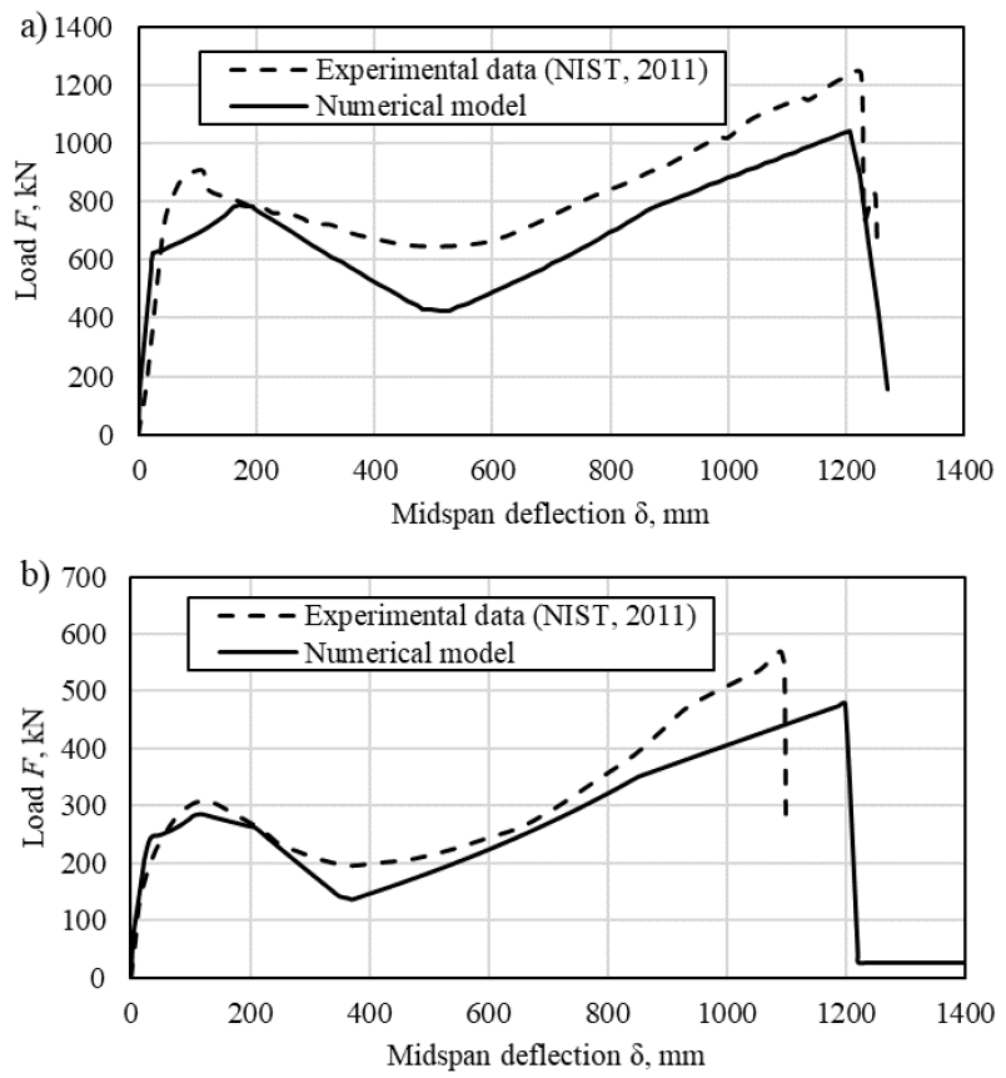

Figure 4. The results of numerical simulation and the results obtained when testing the IMF-specimen (a) and for the SMF-specimen (b) in [18]

As seen from the diagrams shown in Figure 4, the numerical model allows to adequately assess the total nonlinear response of the damaged frame under increasing deflections.

Considering that the energy-based method (EBM) is based on the principle of conservation energy, one of the main parameters characterizing robustness of the structural system is the strain energy of the damaged structural system. The strain energy stored in the deformed system can be calculated through a static nonlinear pushdown analysis. In that case, the strain energy is the area under the static load-deflection curve up to a deflection $\delta_{u l t}$. The strain energy 
used as a criterion for comparing the FE-model simulation results and experimental data.

Under the energy-based method provisions [17, 24, 25, 27], the dynamic resistance of a damaged structural system with a single degree of freedom (SDOF) is calculated by dividing the stored strain energy by the value of the ultimate displacement. Table 6 shows a comparison of the results of numerical simulation with the results obtained experimentally in tests [18].

Table 6. Comparison of calculation results with experimental data

\begin{tabular}{|c|c|c|c|c|c|}
\hline \multirow[t]{2}{*}{ Specimen } & \multirow[t]{2}{*}{ F- $\delta$ reaction } & $\begin{array}{l}\text { Ultimate } \\
\text { static } \\
\text { resistance }\end{array}$ & $\begin{array}{c}\text { Ultimate } \\
\text { displacement }\end{array}$ & $\begin{array}{c}\text { Strain energy } \\
\text { of the damaged } \\
\text { structural system }\end{array}$ & $\begin{array}{l}\text { Ultimate } \\
\text { dynamic } \\
\text { resistance }\end{array}$ \\
\hline & & $F_{u l t}, \mathrm{KN}$ & $\delta_{u l t}, \mathrm{~mm}$ & $E_{\text {int }} \mathrm{kN} \cdot \mathrm{mm}$ & $F_{d, u l t}, \mathrm{kN}$ \\
\hline \multirow{3}{*}{ IMF } & According to $[18]$ & 568 & 1092 & 332840 & 305 \\
\hline & $\begin{array}{c}\text { Numerical } \\
\text { model }\end{array}$ & 478 & 1199 & 339594 & 283 \\
\hline & $\begin{array}{l}\text { Deviation of } \\
\text { the calc. val. } \\
\text { from [18] }\end{array}$ & $-15.85 \%$ & $9.80 \%$ & $2.03 \%$ & $-7.21 \%$ \\
\hline \multirow[t]{3}{*}{ SMF } & $\begin{array}{c}\text { According } \\
\text { to }[18]\end{array}$ & 1236 & 1225 & 1012787 & 827 \\
\hline & Numerical model & 1043 & 1208 & 831467 & 688 \\
\hline & $\begin{array}{c}\text { Deviation of } \\
\text { the calc. val. } \\
\text { from [18] }\end{array}$ & $-15.61 \%$ & $-1.39 \%$ & $-17.90 \%$ & $-16.81 \%$ \\
\hline \multicolumn{6}{|c|}{$\begin{array}{l}\text { Notes: } \\
\text { 1) Strain energy of the damaged structural system } E_{\text {int }} \text { is obtained as the area under the quasi-static } \\
\text { resistance curve F- } \delta \text { (Figure } 4 \text { ) for each case at the corresponding ultimate displacement } \delta_{u l t} \text {; } \\
\text { 2) Ultimate dynamic resistance Fd,ult is derived from formula } \\
F_{d, u l t}=E_{\text {int }} / \delta_{\text {ult }} \text {. }\end{array}$} \\
\hline
\end{tabular}

As seen from the comparison of the results listed in Table 6, the proposed numerical FE-model adequately predicts the response of the damaged structural system, accounting for the development of membrane effects. The deviation of the calculated values of the dynamic resistance from the experimental data was $7.21 \%$ for the IMF-specimen and $16.81 \%$ for the SMF-specimen. These deviations are due to both the statistical uncertainty of the initial data and the modeling uncertainty for the used FE software. At the same time, when assessing the ultimate dynamic resistance of the system, the solutions are more conservative in comparison with the experimental results. The problem concerning the quantitative assessment of the uncertainties of the proposed energy balance method in comparison with nonlinear dynamic analysis (NLD) considers in works [7, 17, 24, 25, 27]. It was noted in [7] that "to avoid cumbersome nonlinear dynamic analyses, the energy-based method (EBM) is promising technique to predict the maximum dynamic responses of structural system". It was found that the uncertainty of modeling the energy-based method in comparison with nonlinear dynamic analysis (NLD) is well described by a lognormal distribution with the following statistical parameters LN $(0.95 ; 0.20)$. It should be noted that the presented results of the estimation of the modeling uncertainty can be attributed only to the results of modeling the experimental structure [7]. A more accurate estimate of the modeling uncertainty is needed using a set of different design solutions. At the same time, the proposed numerical model can be used to carry out parametric studies of the dynamic resistance of a structure, taking into account membrane effects and to check the robustness of structural systems in accidental design situations.

\section{Checking the robustness of a structural system in an accidental design situation. Working example}

\subsection{Short description of the structural system}

As an example, we carried out the assessment of the robustness of the structural system shown in Figure 5a. Based on the provisions [17, 27], discretization of the spatial structural system performs and the behavior of a fragment (Figure 
5c) of one floor (Figure 5b) after the central column removing assess.

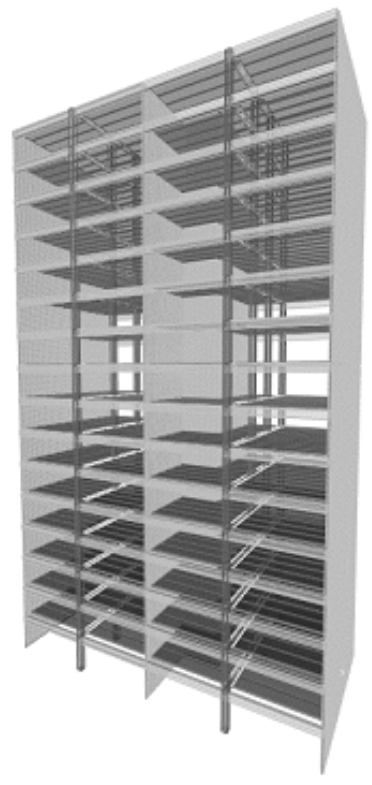

b)

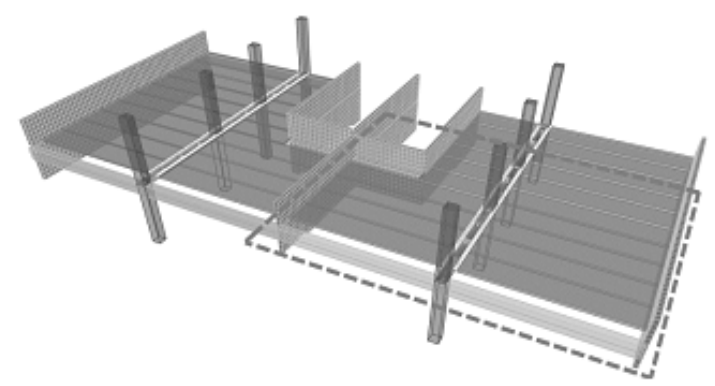

c)

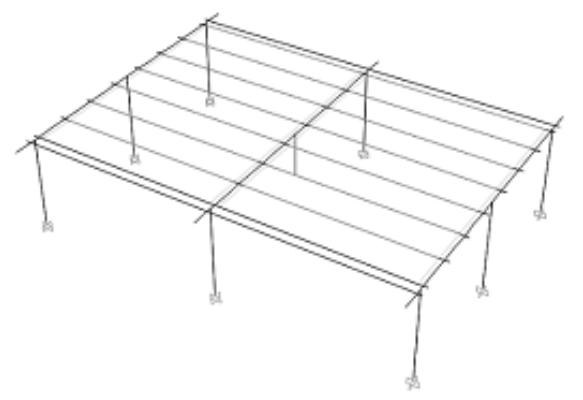

Figure 5. Discretization of the structural system for the robustness checking in an accidental design situation

Figure 6 shows a fragment of the precast hollow-core slabs floor. T-section prefabricated beams are supported by monolithic columns (400x400 mm). Prefabricated hollow-core slabs with a height of $220 \mathrm{~mm}$ support on the flanges of the T-beams in the perpendicular direction. The horizontal ties are designed in accordance with the provisions of the Tie Force (TF)-method [11, 21]. Four reinforcing bars of S240 class with a diameter of $28 \mathrm{~mm}$ are used as horizontal ties of adjacent girders. As horizontal ties for hollow slabs, one bar with a diameter of $28 \mathrm{~mm}$ (S240) was adopted for one end of each slab.

Under the project, the requirements for the continuity of the connections of prefabricated hollow-core slabs are ensured by installing embedded parts in them, to which reinforcing bars (i.e. tie elements) are then welded (Figure 7). The bars are passed through special tubes ("normalized plastic length") pre-installed in the body of the girders. Thus, they provide horizontal connections between hollow-core slabs in the direction of their spans, and also perform a connection between the slabs and the girder, which resists in the perpendicular direction.

As conceived by the authors of the project, it is assumed that such a solution ensures the continuity of the floor elements in two directions and creates alternative load paths in an accidental design situation.

\subsection{Numerical modeling of a structural system}

Girders and columns in the FE-model are represented by linear-elastic beam finite elements. Beam-column joints are modeled using rigid inserts, at the ends of which moment plastic hinges are inserted (to simulate the nonlinear response of the girder and the column during loading). In addition, axial plastic hinges are inserted in the girders, which simulate the behavior of horizontal ties (Figure 8).

Hollow-core slabs are modeled with equivalent beam finite elements that are hinged to the girders. Axial plastic hinges are also inserted in the joints between the slabs and the girder to simulate the horizontal tie of the hollow slabs.

An accidental design situation is considered, according to which, sudden removal of the central column occurs. The FE-model of a floor fragment with a different type of plastic hinges inserted according to the rules given in clause 1.1 is shown in Figure 8.

Non-linear analyses were performed using the average values of the mechanical properties of materials (see Table 7).

The moment plastic hinge describes using the "moment-curvature" relationship (see Figure 9), which got based on results of calculation for the cross-section of the girder at the interface with the column, considering the stress-strain 


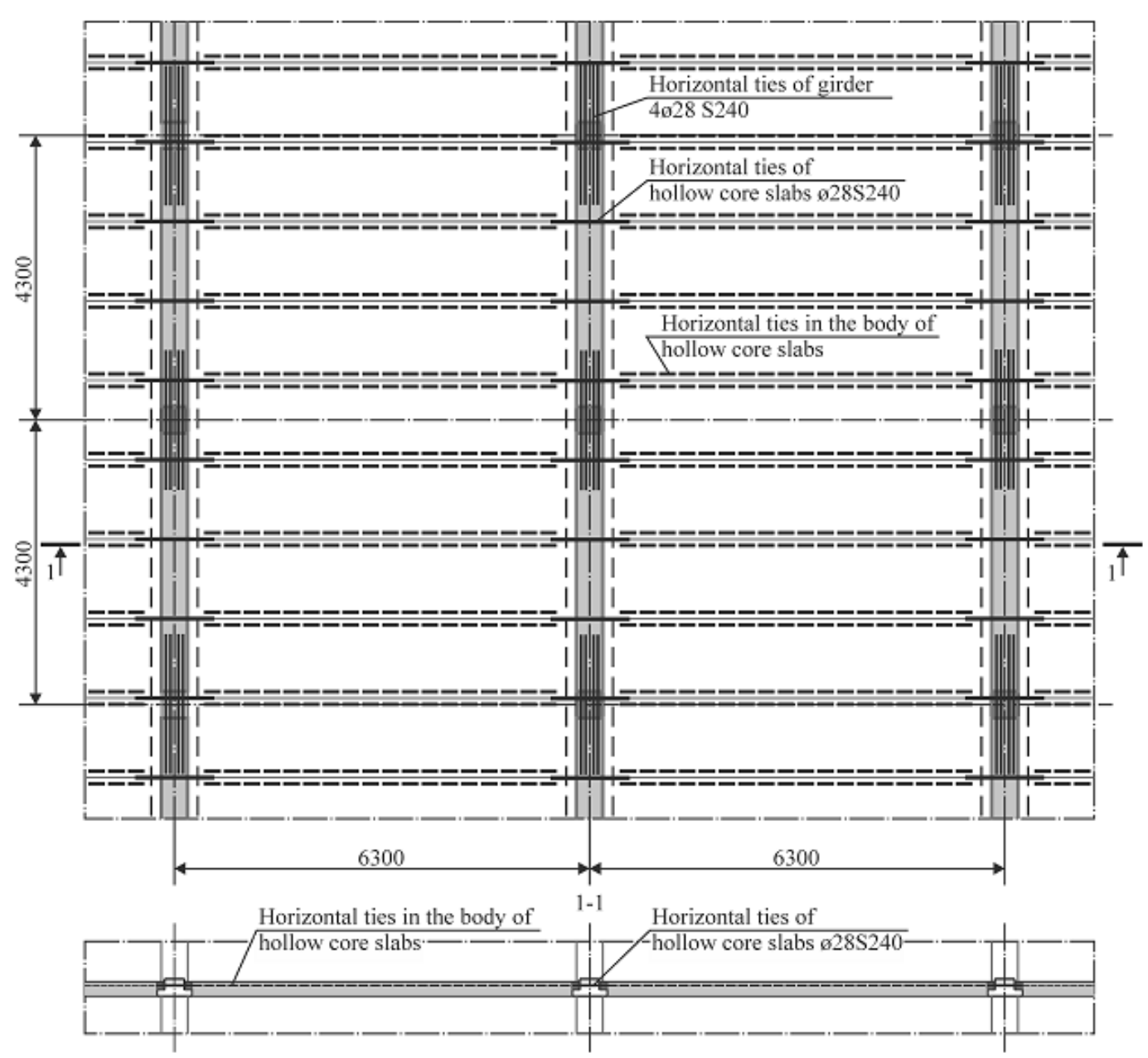

Figure 6. Fragment of the floor with the layout of the horizontal ties

Horizontal ties of hollow core slabs

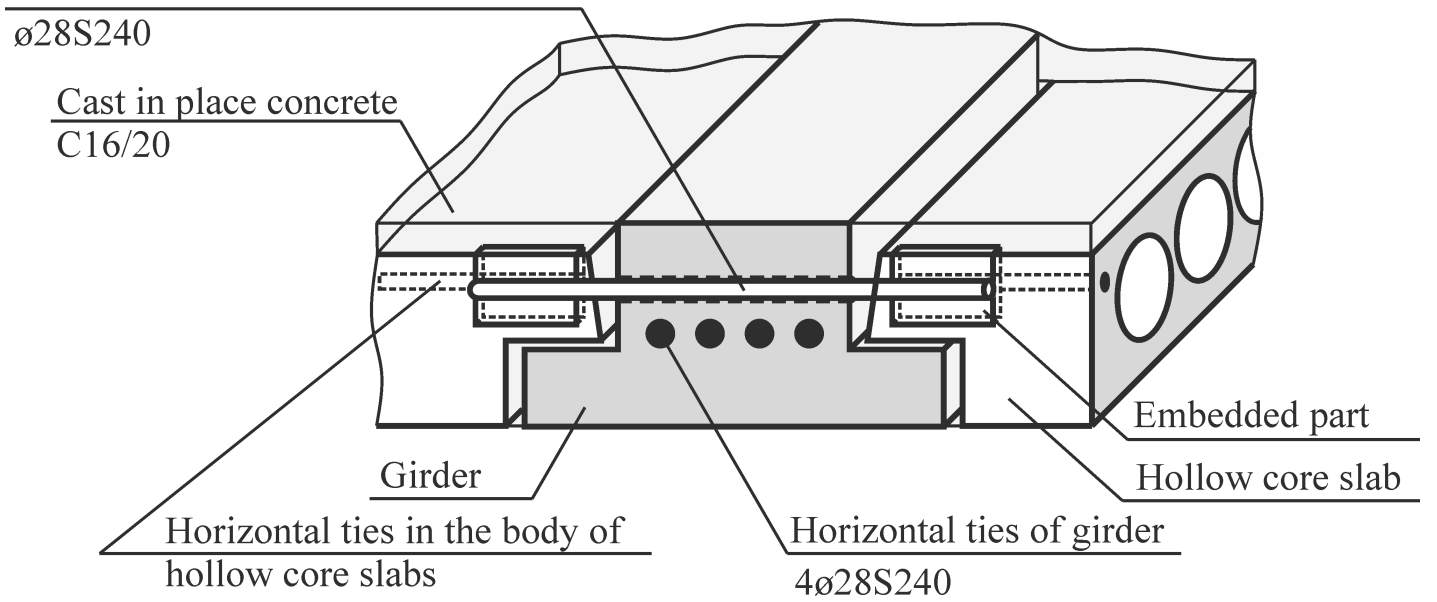

Figure 7. Location of horizontal ties in hollow slabs and girders

relationships for concrete and steel according to SP 5.03.01-2020. The tensile behavior of concrete is governed by 


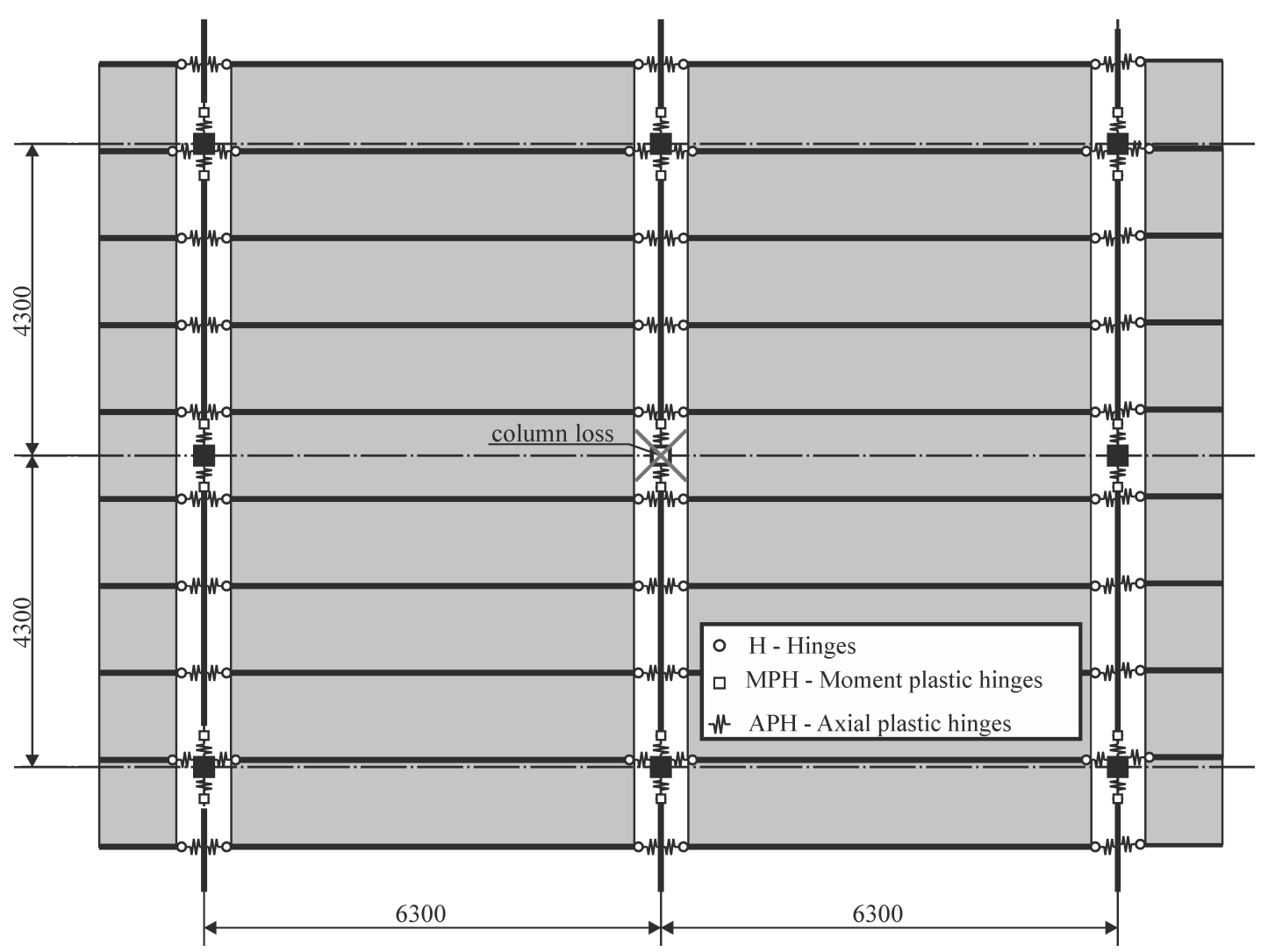

Figure 8. FE model of a slab fragment with horizontal ties after removing the central column

Table 7. Characteristics of material properties

\begin{tabular}{|c|c|c|}
\hline Material & Characteristirs & Structural element \\
\hline Concrete $\mathrm{C} 25 / 30$ & $\begin{array}{r}f_{c m}=33 \mathrm{MPa} ; E_{c m}=31 \mathrm{GPa} ; \\
f_{c t}=2,6 \mathrm{MPa}\end{array}$ & $\begin{array}{c}\text { Columns, girders, } \\
\text { hollow slabs }\end{array}$ \\
\hline Rebar B500 & $\begin{array}{r}f_{y m}=500 \mathrm{MPa} ; f_{u}=540 \mathrm{MPa} ; \\
E_{s}=200 \mathrm{GPa} ; \varepsilon_{u}=5 \%\end{array}$ & \\
\hline Rebar S240 & $\begin{array}{r}f_{y m}=240 \mathrm{MPa} ; E_{s}=200 \mathrm{GPa} ; \\
\varepsilon_{u}=15 \%\end{array}$ & Ties \\
\hline
\end{tabular}

tensile strength and fracture energy, where tensile strength is calculated according to SP 5.03.01-2020. Finally, other default input values for the numerical FE-model are based on the SAP2000 user manual. The length of the plastic hinge was taken equal to the effective section depth $d=230 \mathrm{~mm}$.

The "longitudinal forces-longitudinal displacements" relationship for axial plastic hinges in girders and hollow core slabs are shown in Figure 10. The values at the parametric points of the "N-w" diagrams are obtained based on the equations given in Table 1.

Nonlinear static analysis of the damaged structural system with displacement control in the central joint with the removed key element was performed. The effects of geometric nonlinearity were taken into account when large deflections were realized. As a result, complete nonlinear responses " $q-\delta$ " were obtained. Under the energy-based method $[17,24,25,27]$, the nonlinear quasi-static reaction " $q-\delta$ " was rearranged into the dynamic resistance curve 


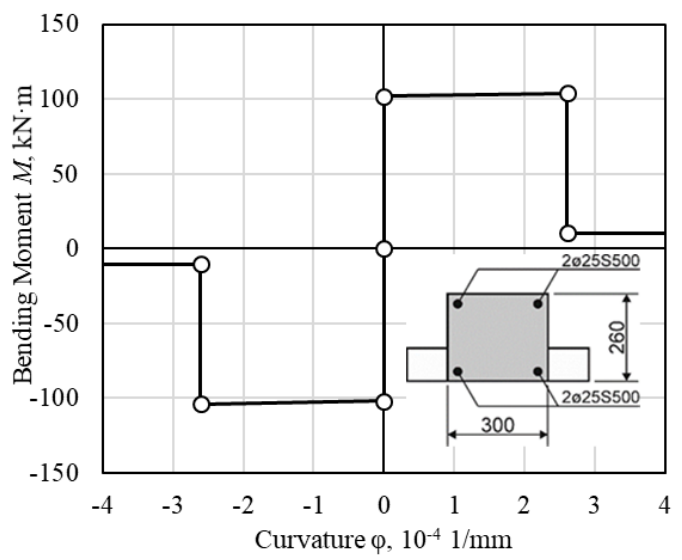

Figure 9. Diagram "moment-curvature" for the critical cross-section of the girder
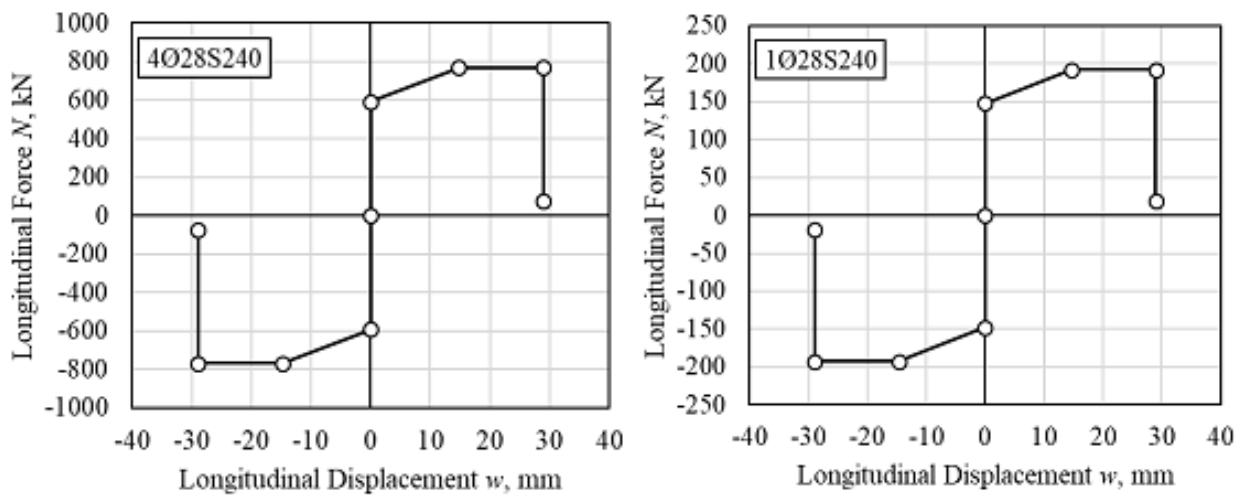

Figure 10. Diagram "longitudinal force-longitudinal displacement" for tie elements

of the damaged system.

\subsection{The results of calculating the strain energy capacity of the structural system. Ultimate dynamic resistance}

According to the conservation of energy law, the robustness of a system with one degree of dynamic freedom will be ensured when the released potential energy upon sudden removal of the key element is compensated by the strain energy of the elements of the damaged system in the first half-period of oscillations (when the kinetic energy of the system is zero).

In the general case, the strain energy capacity of the system consists of several components. In our case, we consider the contribution from the bending resistance and tensile resistance of horizontal ties of reinforced concrete girders in one direction and only horizontal ties resistance of precast hollow slabs in the transverse direction. This approach makes it possible to quantify the contribution of the horizontal ties to the global resistance of the structural system.

In this example, we will first analyze the behavior of the entire spatial (3D) system. Then we will separately consider the behavior of individual resistance mechanisms and their contribution to the total strain energy capacity of the system when the central column is suddenly removed for the floor fragment shown in Figure 8.

The Figure 11 shows the results of a nonlinear simulation of the response of a damaged floor fragment considering contribution of the horizontal ties. This figure dashed line shows the reconstructed dynamic diagram describes dynamic response of the system.

As seen from the results of nonlinear analysis (Figure 11), the following characteristic stages can be distinguished in the behavior of a spatial system with removed column: 


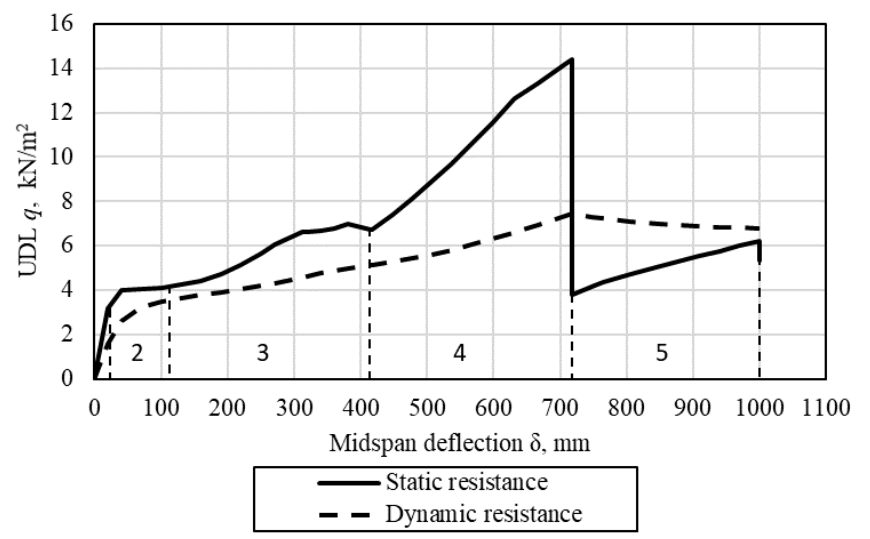

Figure 11. Summarized nonlinear response of a damaged floor fragment considering horizontal ties

1) Linear elastic stage. The elastic response of the system is entirely due to the elastic behavior of the linear bar elements.

2) The stage of the plastic bending of the girders. It begins with the achievement of the yielding of the reinforcing steel. The increase in deflections is due to the development of the angles of rotation in the moment plastic hinges ("First line of defense").

3) Intermediate stage. This stage is characterized by the further development of moment plastic hinges until the ultimate bending angles of rotation are reached. At the same time, vertical deflections are achieved for the development of longitudinal tensile forces in the horizontal ties of the girder. The contribution from ties to the total resistance of the system at this stage is insignificant.

4) Stage of tensile membrane (chain effects). At this stage, the contribution from the bending of the girder to the resistance of the system is insignificant or completely absent, yielding in the steel horizontal ties achieves. Horizontal ties provide a resistance of the system, both in the girders and in the central hollow slabs (slabs between the distant and adjacent columns).

The first peak on the " $q-\delta$ " response (see Figure 11) is associated with the achievement of ultimate tensile strain in the horizontal ties of the girders. After that, there is a sharp drop in static response to a level that is provided by the resistance of the system of horizontal ties of hollow-core slabs in the perpendicular direction.

5) The stage of sequential failure of ties (zipper type collapse). After the failure of the horizontal ties of the girders, the residual resistance is provided only by the horizontal ties of the slabs. In this case, the maximum membrane forces arise in the ties of the central slabs located in the column strip. In these ties the ultimate tensile strains will be achieved.

The second peak on the static response associated with the failure of the horizontal ties of the central slabs, after which the calculation procedure was stopped. Although it is theoretically possible to further redistribute the forces to the remaining adjacent slabs, however, in this case the contribution to the total strain energy is insignificant for increasing the ultimate dynamic resistance of the remaining slab. As seen from the responses shown in Figure 11, the first peak in the static response coincides with the peak in the dynamic resistance curve. With a further increase in vertical displacements, the dynamic resistance of the system decreases (although the strain energy capacity increases!). This indicates that if the gravity load insignificantly exceeds the peak value of the dynamic resistance, the girder will fail and the subsequent uncontrolled failure of the horizontal slab ties (zipper-type collapse) will occur.

Let us analyze the contribution from each resistance mechanism to the robustness of the damaged structural system separately.

First, consider the response of a reinforced concrete 2D-frame with the center column removed (Figure 12a). The FE-model with plastic hinges inserted in according to the above rules is shown in Figure 12b.

To quantify the contribution from frame bending to the total resistance, consider the FE- model without axial plastic hinges (Figure 12c). When assessing the contribution from horizontal ties, moment plastic hinges in the numerical model are replaced by simple hinges (Figure 12d). 
a)

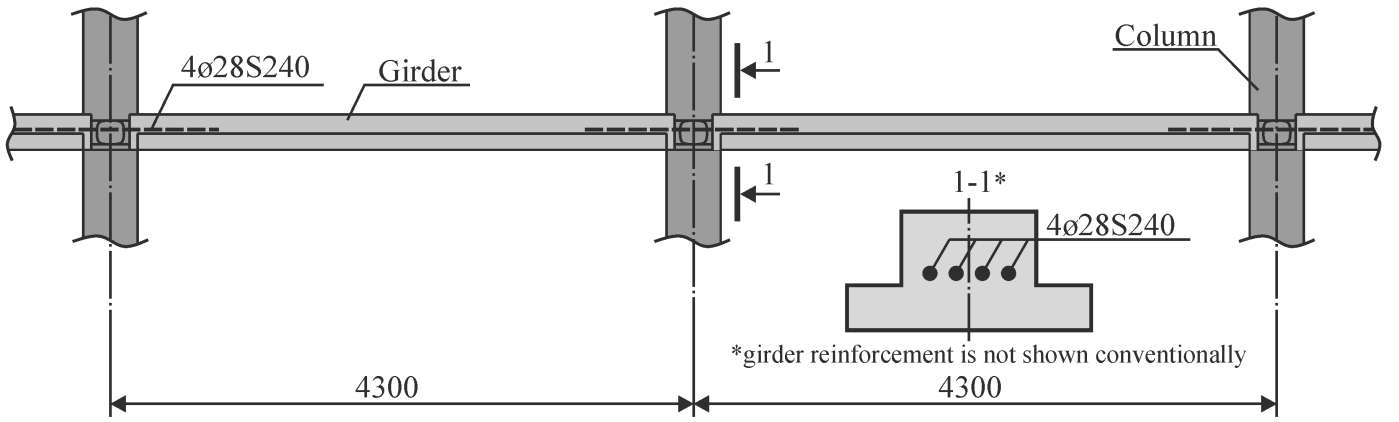

b)

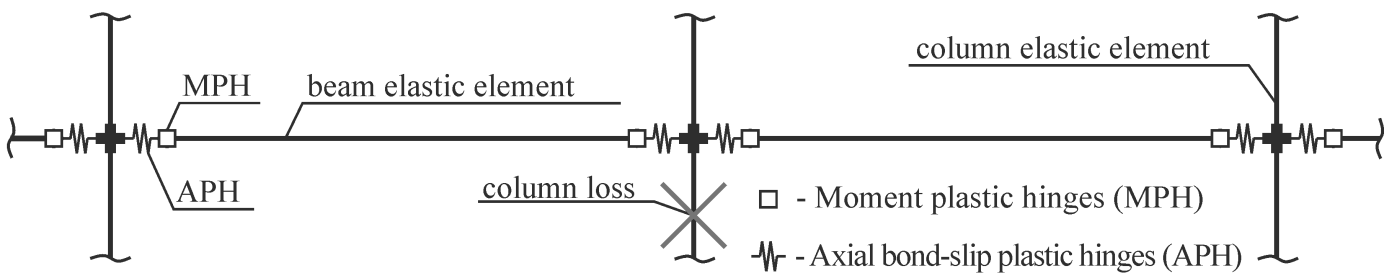

c)

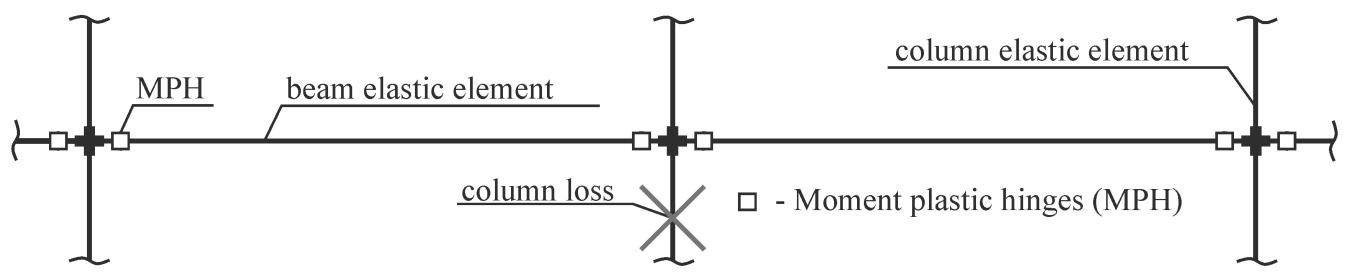

d)

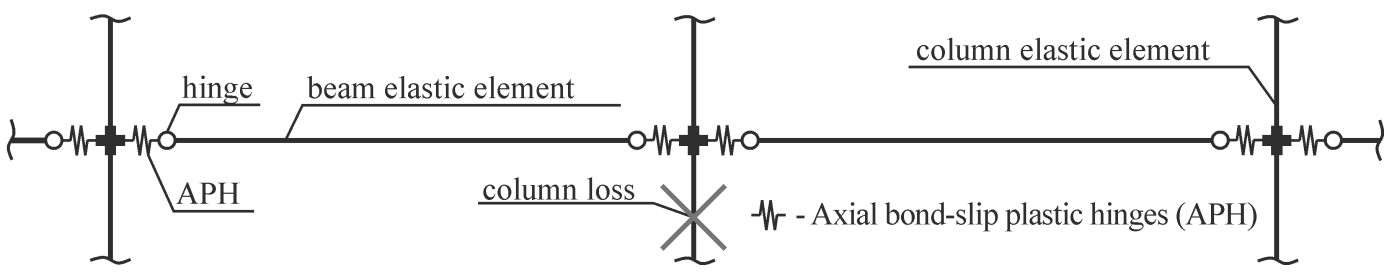

Figure 12. Structural scheme (a), FE-model of the flat frame (b), FE- model of a flat frame considering only bending behavior (c), FE- model considering only horizontal ties (d)

The results of calculations for various variants of FE-models (from Figure 12) in the form of nonlinear quasi-static responses are shown in Figure 13.

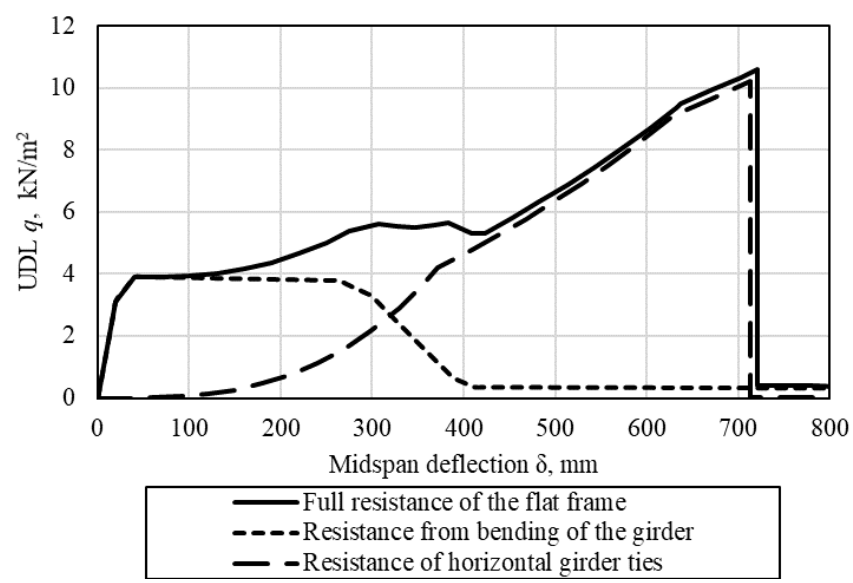

Figure 13. Nonlinear responses of the flat frame 
To assess the contribution from the reaction of the horizontal ties of the slabs to the total dynamic resistance, the following calculation scheme is considered. The central girders work as elastic elements without moment and the outer columns pivotally supported plastic hinges. It does not take longitudinal horizontal ties in girders into account in the calculation. Thus, the girders perform the function of an intermediate connecting element for perpendicular floor slabs. The FE-model is shown in Figure 14.

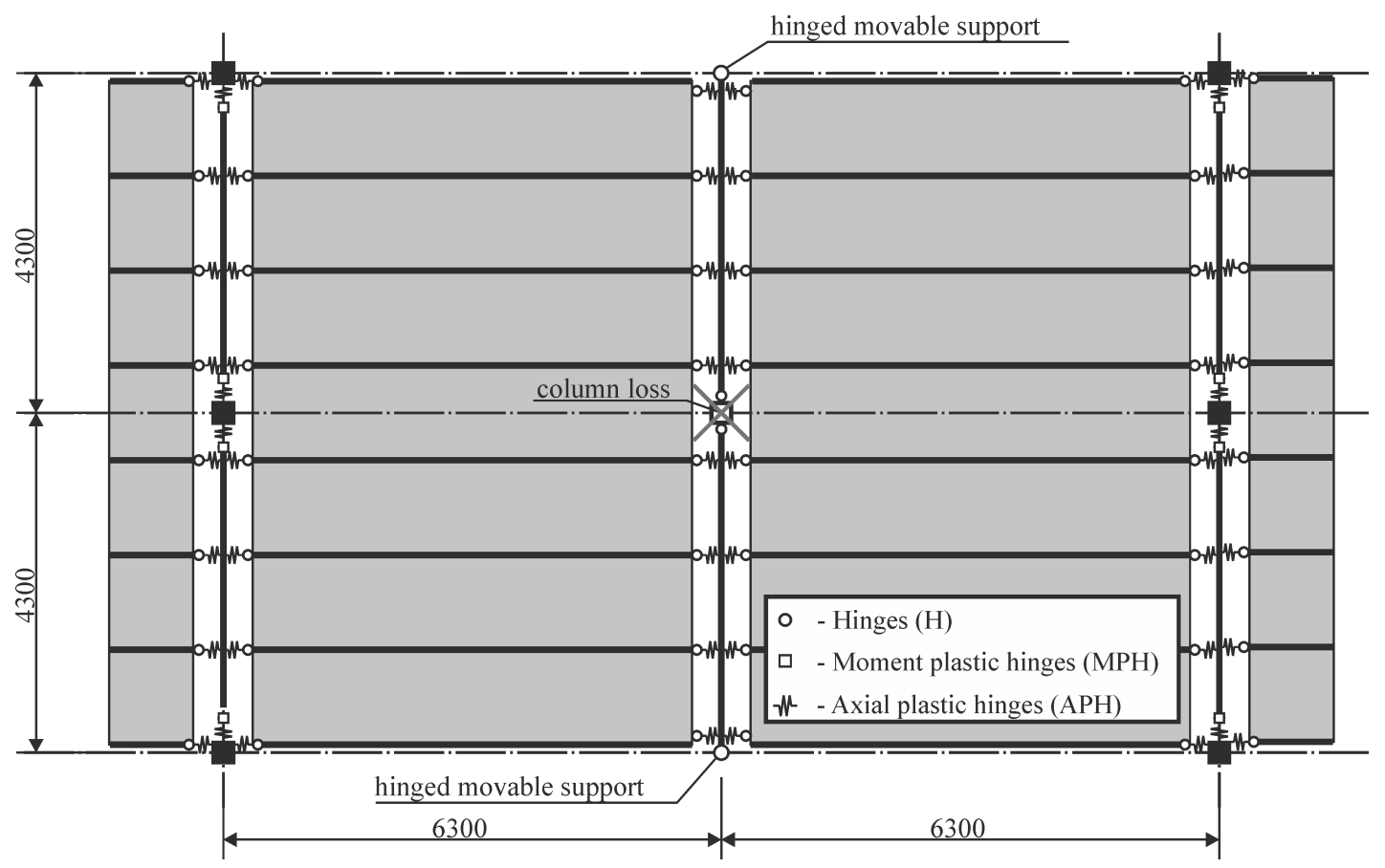

Figure 14. FE-model for assessing the resistance of horizontal ties of hollow slabs

We performed nonlinear analysis in the same conditions as for the original structural system. The Figure 15 presents the results of a nonlinear analysis of the quasi-static resistance of horizontal ties of hollow slabs in comparison with the total resistance of the spatial 3-D system.

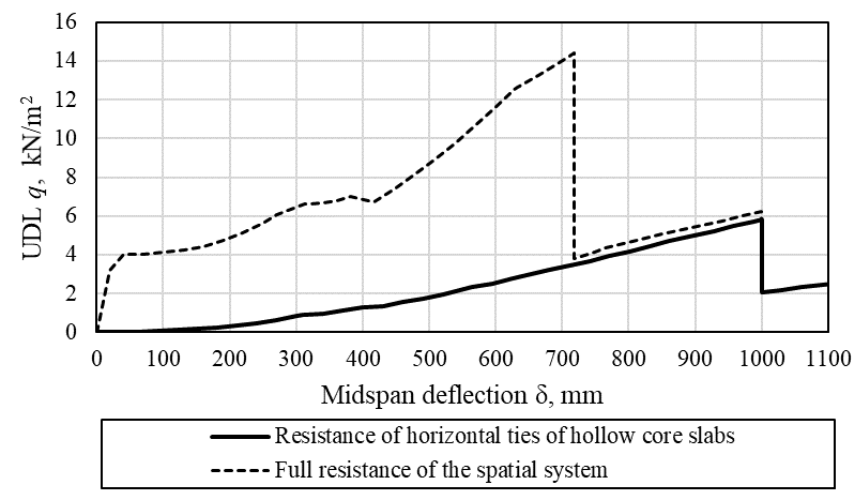

Figure 15. Resistances of horizontal ties of hollow slabs in comparison with the total resistance of the system

\subsection{Analysis of the numerical simulation results}

The results of simulation of the nonlinear static response and dynamic resistance of a floor fragment with horizontal ties and the contribution from each individual resistance mechanism for the case of removing the central column are shown in Figures 16 and 17.

The contribution from each resistance mechanism to the total strain energy capacity of the system will be determined with a constant vertical displacement equal to $716.7 \mathrm{~mm}$, which corresponds to the first peak of the full quasi-static response curve and the maximum value of dynamic resistance (see Table 8). 


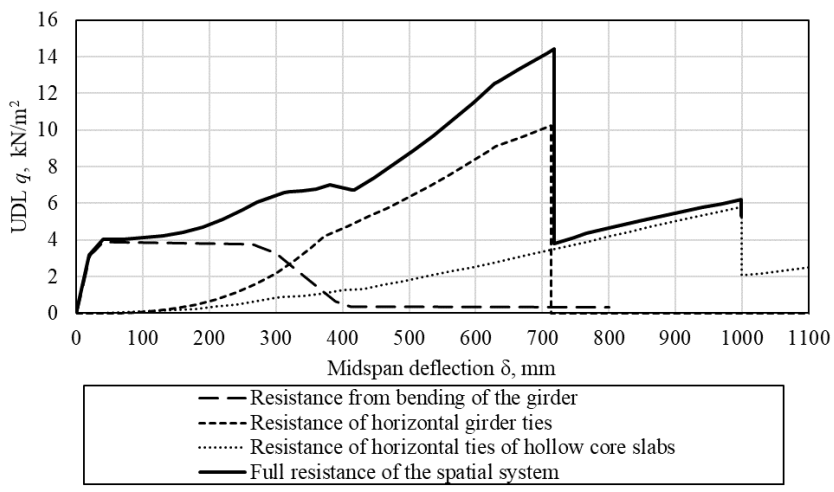

Figure 16. Results of nonlinear simulation of the spatial system response and the contribution of each individual resistance mechanisms

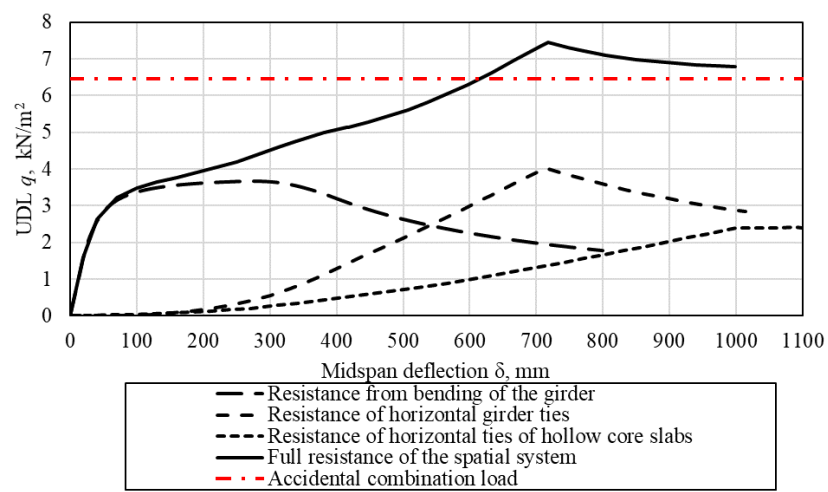

Figure 17. Diagrams of dynamic response for the spatial system and individual mechanisms of resistances

Table 8. Estimation of the strain energy capacity of the structural system

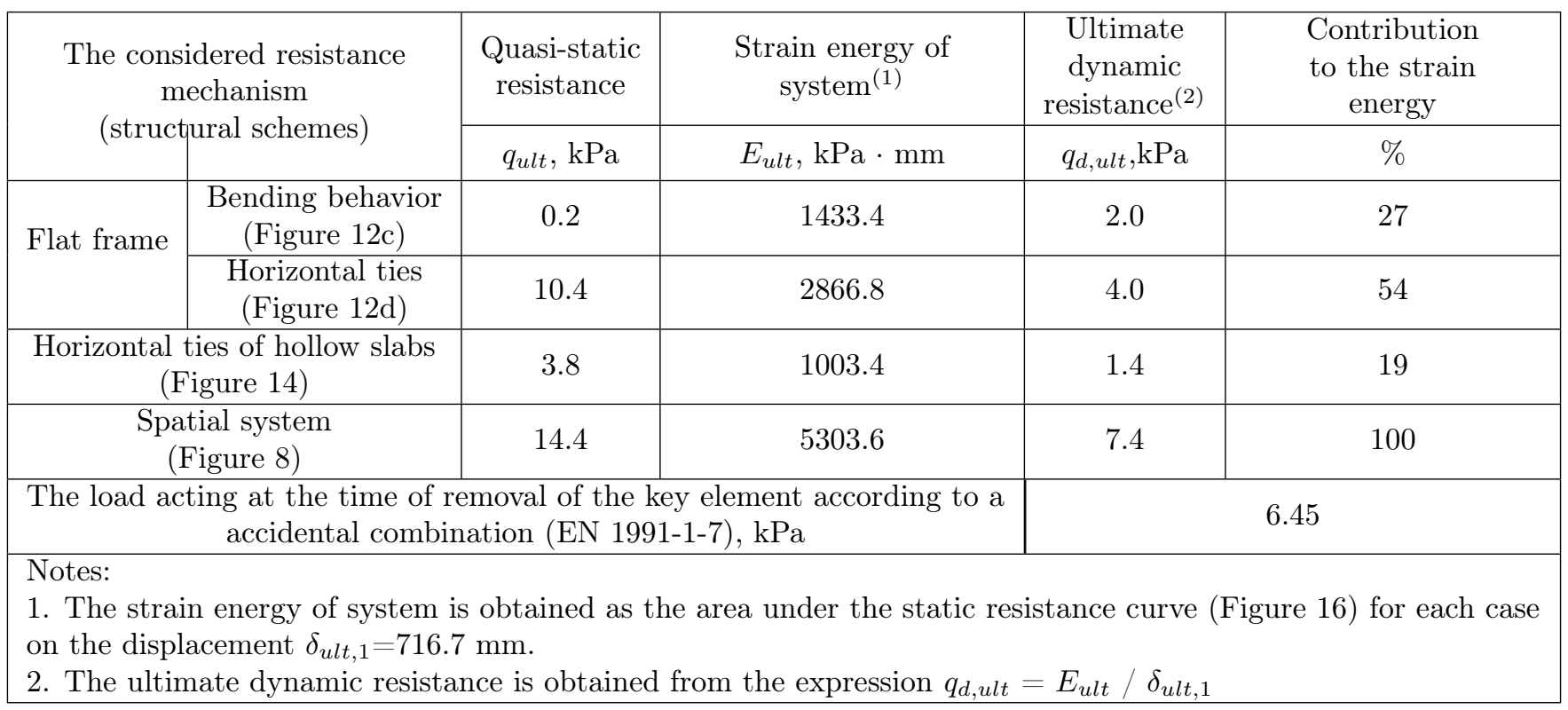

A detailed analysis of individual resistance mechanisms clearly shows that at the initial stages (elastic and plastic stages), the strain energy capacity is due to the elastic and plastic bending behavior of girders and columns. When the vertical deflections are sufficient for the development of tensile longitudinal forces, the horizontal ties in the girder 
and in the floor slabs are included in the resistance and contribute to the total strain energy capacity of the system. At the stage of the tensile membrane (chain effects), the contribution from the bending of the girder to the resistance of the system is practically absent. Yield strains are achieved in ties.

The behavior of a complete system can be described as the behavior of a system of parallel connected resistance mechanisms with different strain energies (bending resistance of girders + resistance of horizontal ties of girders + resistance of horizontal ties of hollow slabs). The combined operation of all resistance mechanisms of the system characterizes the behavior of the damaged system up to the first peak in the quasi-static response. Despite of the nonlinear behavior of the system, the principle of superposition of resistances (quasi-static and dynamic) of individual resistance mechanisms on the corresponding deflections is valid. Reaching the ultimate resistance in one element of the system leads to its failure at the corresponding displacement level (for example, the first peak on the resistance curve) and redistribution of the strain energy. There is a sharp drop in total resistance by an amount equal to the resistance of the failed element. A sharp drop in resistance should be avoided during design, as it can lead to undesirable dynamic effects.

If it is necessary to increase the robustness of this system, then several options can be considered for this. For example, an increase in the resistance of horizontal connections of floor slabs. This option leads to an increase in the total resistance at the first peak point, but the magnitude of the drop in resistance with a further increase in deflections will remain equal to the resistance of the frame at the corresponding displacement. Hence, an increase in the plastic deformability (ductility) of the girders can be an option for reducing this drop. In this way, an optimal solution can be found in the balance between ultimate resistance and ultimate displacement.

\section{Conclusion}

Based on the presented studies, we made the following conclusions.

1. The proposed numerical model makes it possible to adequately describe the behavior of a damaged structural system in an accidental design situation, to carry out parametric studies and to check the robustness of building structures.

2. It has been established that for a reliable determination of the value of the dynamic response of the system, it is necessary to have its total nonlinear quasi-static response, considering the combination of all possible resistance mechanisms. At the same time, it was found that, despite of the nonlinear response of the system, the principle of superposition for the strain energy capacity and dynamic resistance is valid. This makes it possible to determine the components of the total dynamic resistance using simplified models, and then to analyze their common effect.

\section{References}

1. Adam, J., Parisi, F., Sagaseta, J. \& Lu, X. Research and practice on progressive collapse and robustness of building structures in the 21st century. Engineering Structures 173, 122-149 (2018).

2. ASCE. Minimum design loads for buildings and other structures (American Society of Civil Engineers, 2005).

3. Bond and anchorage of embedded reinforcement: Background to the fib Model Code for Concrete Structures 2010: Technical report. fib-Fédération internationale du béton,72 2014.

4. British Standard BS 8110-11. The structural use of concrete in building - Part 1: Code of practice for design and construction Londyn, U.K., 1997.

5. Bulletin 43: Structural connections for precast concrete buildings. Guide to good practice 2008.

6. Byfield, M., Mudalige, W., Morison, C. \& Stoddart, E. A review of progressive collapse research and regulations. Proceedings of the Institution of Civil Engineers-Structures and Buildings 167, 447-456 (8 2014).

7. Ding, L., Van Coile, R., Botte, W. \& Caspeele, R. Quantification of model uncertainties of the energy-based method for dynamic column removal scenarios. Engineering Structures 237 (2021).

8. DoD UFC Guidelines. Design of Buildings to Resist Progressive Collapse, Unified Facilities Criteria (UFC) 4-023-03. Department of Defense (DoD) 2005.

9. El-Tawil, S., Li, H. \& Kunnath, S. Computational simulation of gravity-induced progressive collapse of steel-frame buildings: Current trends and future research needs. Journal of Structural Engineering 140 (8 2014).

10. Ellingwood, B. et al. Best practices for reducing the potential for progressive collapse in buildings. (2007).

11. European Committee for Standardization. Eurocode 1-EN 1991-1-7: Actions on structures - Part 1-7: General actions - Accidental actions. 2006. 
12. Fang, Z. \& Fan, H. Redundancy of structural systems in the context of structural safety. Procedia engineering 14, 2172-2178 (2011).

13. fib Model Code for Concrete Structures 2010. International Federation for Structural Concrete (fib) Lausanne, Switzerland, 2010.

14. Folić, R. Structural Robustness of monolitic and precast RC building in. First Scientific-applied Conference with International Participation Reinforced Concrete and Masonry Structures-Theory and Practice (Sofia, 2015).

15. General Service Administration (GSA). Progressive collapse analysis and design guidelines for new federal office buildings and major modernization projects Washington (DC), 2003.

16. ISO 2394: General principles on reliability for structures, Fourth ed. Geneve, Switzerland, 2015.

17. Izzuddin, B., Vlassis, A., Elghazouli, A. \& Nethercot, D. Progressive collapse of multi-storey buildings due to sudden column loss-Part I: Simplified assessment framework. Engineering structures 30, 1308-1318 (5 2008 ).

18. Lew, H. et al. An experimental and computational study of reinforced concrete assemblies under a column removal scenario. NIST Technical Note, 1720, 1062011.

19. Qian, K. \& Li, B. Research advances in design of structures to resist progressive collapse. Journal of Performance of Constructed Facilities 29 (5 2015).

20. SN 2.01.01-2019. Basics of design of building structures Minsk, Russian, 2020.

21. SP 5.03.01-2020. Concrete and reinforced concrete structures Minsk, Russian, 2020.

22. Tohidi, M. Effect of floor-to-floor joint design on the robustness of precast concrete cross wall buildings Doctoral dissertation (University of Birmingham, 2015).

23. Tur, A., Tur, V., Derechennik, S. \& Lizahub, A. An innovative safety format for structural system robustness checking. Budownictwo i Architektura 19, 067-079 (4 2020).

24. Tur, A., Tur, V.\& Lizahub, A. An innovative approach to safety format of non-linear analysis applied to structural robustness assessment. Budownictwo i Inżynieria Środowiska 9 (3 2018).

25. Tur, A., Tur, V. \& Lizahub, A. Reliability Approaches to Modeling of the Nonlinear Pseudo-static Response of RC-structural Systems in Accidental Design Situations. Journal of Sustainable Architecture and Civil Engineering 22, 76-87 (1 2018).

26. Tur, V., Tur, A. \& Derechennik, S. Proceedings of the Brest State Technical University. Civil Engineering and Architecture 119, 2-15 (1 2020).

27. Vlasis, A., Izzuddin, B., Elghazouli, A. \& Nethercot, D. Progressive collapse of multi-storey buildings due to sudden column loss-Part II: Application. Engineering Structures 30, 1424-1438 (5 2008). 